\title{
Photocatalytic Degradation Of Methyl Orange From Aqueous Solution By Using Chitosan Silica Composite
}

\author{
Makeswari Mayilsamy 1,*(D), Saraswathi Palanisamy ${ }^{2}$ \\ 1 Department of Chemistry, Karpagam Academy of Higher Education, Coimbatore-641021, Tamil Nadu, India \\ 2 Esha college of Engineering and Technology, Coimbatore, Tamilnadu, India \\ * Correspondence: makeswari.chem22@gmail.com;
}

Scopus Author ID 55504962200

Received: 14.10.2020; Revised: 16.11.2020; Accepted: 20.11.2020; Published: 22.11.2020

\begin{abstract}
In this paper, Chitosan Silica Composite (CSC) was prepared successfully. It was effectively used as a photocatalyst in the degradation process of Methyl Orange from the aqueous medium under sunlight irradiation. The photocatalytic degradation studies were carried out by varying contact time, $\mathrm{pH}, \mathrm{CSC}$ dosage, and concentration of Methyl Orange. The maximum degradation percentage of Methyl Orange onto CSC was $94.01 \%$, indicates that it has good degradation ability towards anionic dyes. The results revealed that Methyl Orange degradation was very high in an acidic medium ( $\mathrm{pH} 4)$ at 70 minutes, and the optimum CSC dosage (0.1g). The initial dye concentration of Methyl Orange was fixed as $10 \mathrm{ppm}$. The experimental data were interpreted using adsorption isotherm models like Freundlich, Langmuir, and kinetic models such as Pseudo first order and second order. The results revealed that Methyl Orange's adsorption onto CSC obeys Langmuir Isotherm model shows monolayer adsorption on the composite surface, and it follows Pseudo second order kinetics. $\mathrm{Q}_{\mathrm{m}}$ (maximum adsorption capacity) for the adsorption of Methyl Orange onto CSC was $12.19 \mathrm{mg} / \mathrm{g}$.
\end{abstract}

Keywords: photocatalytic degradation; CSC; Methyl Orange; Langmuir isotherm; pseudo second order kinetics.

(C) 2020 by the authors. This article is an open-access article distributed under the terms and conditions of the Creative Commons Attribution (CC BY) license (https://creativecommons.org/licenses/by/4.0/).

\section{Introduction}

Globalization, industrialization, and developmental activities were the initiators for producing various types of organic pollutants like pesticides, fertilizers, heavy metals, and dyes [1]. Discharge of these pollutants into the water environment causes harmful effects to humans, plants, and animals. The raw materials that are commonly used in dyes are hydrocarbons, benzene, toluene, naphthalene, and Anthracene [2]. Methyl Orange was a commonly used anionic dye in the textile, food, and leather industries [3]. It was also used as an indicator in laboratories. This dye's release may cause numerous health problems in a human being, like irritation of the eye, respiratory tract, and skin [4]. Hence it was essential to remove Methyl Orange dye from wastewater before discharging into aquatic streams.

Several techniques have been employed for dye removal from wastewater such as adsorption [5], coagulation[6], Ozonation[7], electrodialysis[8], biological degradation and photocatalytic degradation [9], in which photocatalytic degradation process has been considered as the most favorable technique in wastewater treatment due to its advantages such as no sludge formation, utilization of naturally occurring energy like solar energy than other alternative energy sources, ease of high scale operation and high potential to remove dyes [10, 
11]. The solar light activity is supported by the enhancement in electrochemical and electronic properties as well as the adsorption process throughout the entire photocatalytic oxidation process. The researchers made a number of attempts for methyl orange removal using various materials such as Chitosan/kaolin $/ \gamma-\mathrm{Fe}_{2} \mathrm{O}_{3}$ composites[12], Chitosan-g-Poly(acrylamide)/ZnS [13], Chitosan/MgO composite [14] Core-Shell $\mathrm{Fe}_{3} \mathrm{O}_{4} / \mathrm{SiO}_{2} / \mathrm{TiO}_{2}$ Nanospheres [15], Fly Ash Modified Copper Oxide (FA/CuO) [16], Chitosan/Polyvinyl Alcohol/Zeolite Electrospun Composite Nanofibrous Membrane [17].

Deacetylation of chitin yields chitosan, or it was obtained from crab shrimps. Chitosan was the second abundant naturally occurring polysaccharide next to cellulose. It has several $\mathrm{OH}^{-}$and an $\mathrm{NH}_{2}$ groups, with its structure as the primary reason to choose a prime material to remove pollutants from wastewater. Due to its reduced flocculation property, the degradation capacity was moderate in wastewater treatment. To increase chitosan degradation capacity, it can be modified by grafting (inserting various functional groups) or cross-linking process [18].

Silica possesses good degradation capacity, easy to form a chemical compound with organic materials to produce various silica modified surfaces, thermal stability, low-cost, and it is inert in nature. It has good ion exchange capacity and highly porous [19]. The abovementioned advantages are the primary reason to choose silica as a modification material with chitosan. Noval mesoporous Silica-Chitosan composites have been utilized for the removal of pollutants from industrial wastewater such as $\mathrm{Hg}$ (II) [20], Rhenium(VII) [21], Sulphonated dyes[22], Adsorptive removal of lead $(\mathrm{Pb})$, copper $(\mathrm{Cu})$, nickel $(\mathrm{Ni})$ and mercury $(\mathrm{Hg})$ ions [23].

The objective of this research work is to determine the degradation capability of CSC towards Methyl Orange dye by batch mode photocatalytic degradation studies by varying contact time, $\mathrm{pH}, \mathrm{CSC}$ dose, and initial dye concentration.

\section{Materials and Methods}

A typical anionic dye Methyl Orange with a molecular formula of $\mathrm{C}_{14} \mathrm{H}_{14} \mathrm{~N}_{3} \mathrm{NaO}_{3} \mathrm{~S}$ was used as a sample dye to investigate the degradation ability of CSC. Chitosan, Silica gel, $\mathrm{HCl}$, $\mathrm{NaOH}$, acetic acid, and ethanol was procured from Universal Scientific Company, Coimbatore (Tamil Nadu).

The preparation and characterization of the CSC were reported in our previous paper [24].

\subsection{Preparation of Chitosan Silica Composite (CSC)}

Chitosan was dissolved in 5\% acetic acid solution, and the slurry was stirred for 2 hours in a magnetic stirrer. To this mixed slurry, silica gel was added, and the stirring was continued for another one hour to reach homogeneity. The bubble-free mixture was produced after 8 hours by keeping the mixture at room temperature at a stable place. 2:1 was the weight ratio of chitosan and silica gel in this reaction. After 8 hours, $\mathrm{NaOH}$ and ethanol were added with the bubble-free mixture and kept aside for 24 hours to form Chitosan Silica Composite (CSC). To remove the impurities from the solution, the product was washed well with double distilled water. The final product was filtered and dried in a hot air oven at $55^{\circ} \mathrm{C}$ for 6 hours. The dried composite was crushed, powdered, and stored in an airtight container for further studies [25]. 


\section{Results and Discussion}

\subsection{Photocatalytic degradation studies.}

Photocatalytic degradation studies were carried out by varying contact time, $\mathrm{pH}, \mathrm{CSC}$ dose, and initial dye concentration. Methyl Orange stock solution was prepared by $1 \mathrm{~g}$ of dye dissolved in one liter of water. It was used for degradation studies. $50 \mathrm{ml}$ of various concentrations of stock solution were taken in a series of conical flasks with a known amount of $\operatorname{CSC}(0.1 \mathrm{~g})$ at different $\mathrm{pH}$ ranges (2-8), and the whole mixture was stirred well and kept in a bench shaker for 10 minutes to reach the equilibrium condition. After reaching the equilibrium condition, the solution was exposed to direct sunlight. The absorbance was measured at regular interval time with the range of 200-800 nm using UV-Visible spectrophotometer119 for the exposed dye solution after centrifugation. The experiments were duplicated, and the mean values were reported. The following equation determined the photocatalytic degradation efficiency of CSC towards Methyl Orange

$$
\eta=\frac{A_{0}-A_{t}}{A_{0}}
$$

Where $A_{0}$ is the initial dye absorbance, and $A_{t}$ is the dye absorbance after dye degradation $[26,27]$.

\subsubsection{Effect of contact time.}

The effect of contact time for the degradation of Methyl Orange onto CSC using sunlight irradiation was studied by varying the time from 10-80 minutes. The relationship was shown in Fig. 1. When the contact time increases, there was a gradual increase in $\%$ of degradation up to 70 minutes. After 70 minutes, no remarkable change in $\%$ of degradation indicates that the presences of active sites in the composite were high at the earlier stage. At the later stage, the presence of active sites was less due to the accumulation of dye molecule over CSC's surface [28]. From the results, the maximum degradation of Methyl Orange was observed as $94.01 \%$ at 70 minutes, and the optimum dose of CSC. Therefore it could be fixed as optimal contact time for the entire studies.

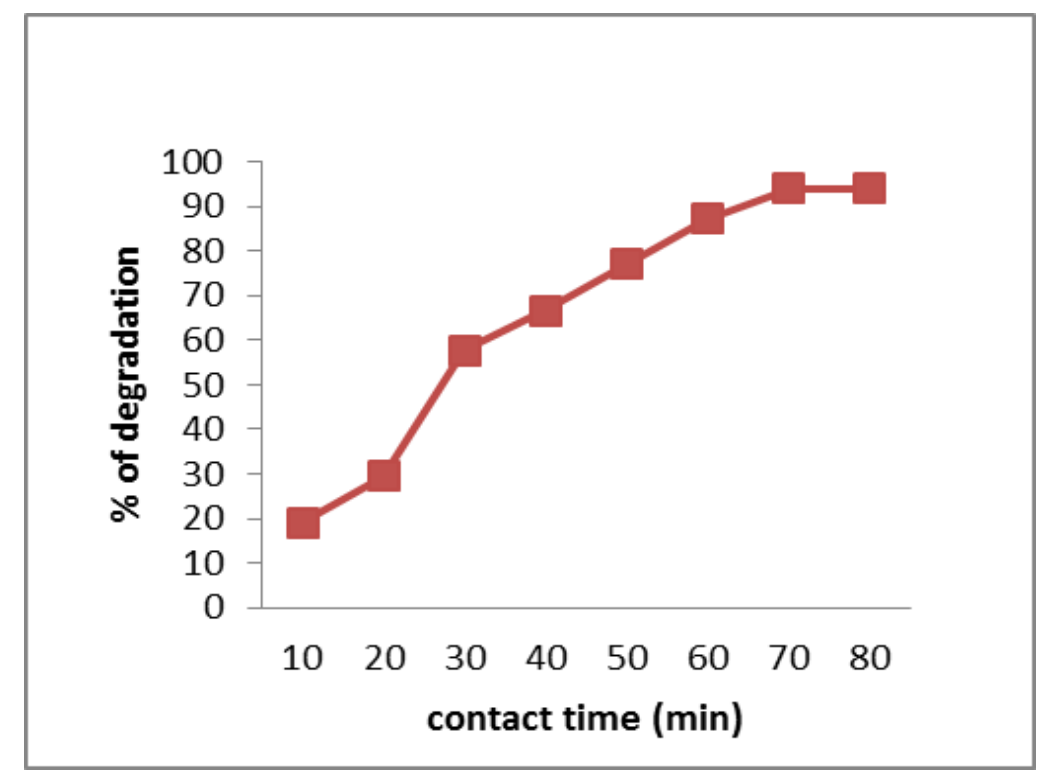

Figure 1. Effect of contact time on the Methyl Orange degradation onto CSC. 


\subsubsection{Effect of $\mathrm{pH}$.}

The solution $\mathrm{pH}$ influences the functional groups present in CSC and the charge of the composite. The effect of $\mathrm{pH}$ was studied by varying the $\mathrm{pH}$ ranges from 2-8, and the relationship between $\mathrm{pH}$ and \% of degradation was depicted in Fig. 2. Maximum degradation of Methyl Orange $(94.01 \%)$ occurs at the $\mathrm{pH}$ of 4 . When increasing the solution's $\mathrm{pH}$, Methyl Orange gradually degrades. This may be attributed that the effect of $\mathrm{pH}$ depends on the zero point charge of CSC. The zero point charge of CSC was 7.8. If the solution $\mathrm{pH}$ was below the zero point charge, if favors anionic dye degradation since the charge of the composite was positively charged $\left(\mathrm{H}^{+}\right)$, and if the solution $\mathrm{pH}$ was below the zero point charge, if favors cationic dye degradation because CSC was negatively charged $\left(\mathrm{OH}^{-}\right)$[29].

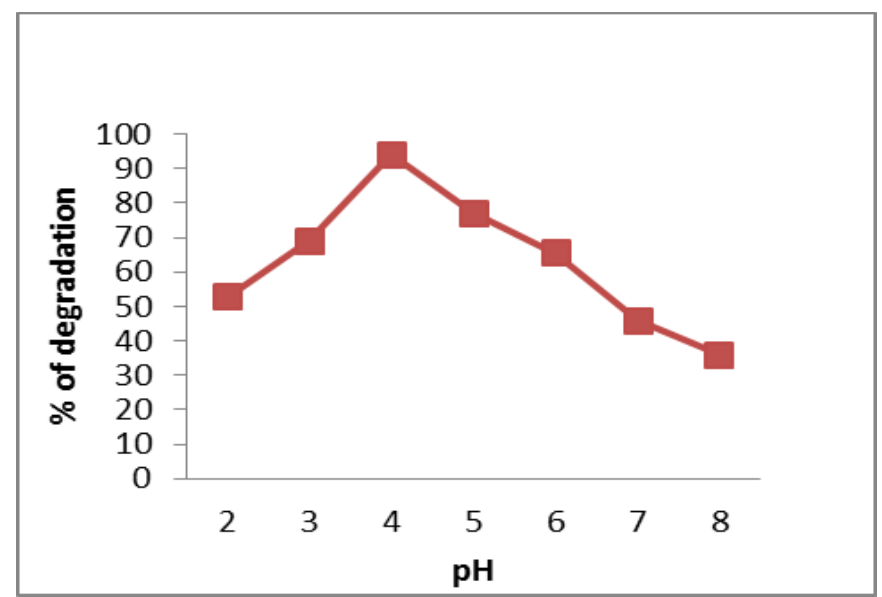

Figure 2. Effect of pH on Methyl Orange degradation onto CSC.

\subsubsection{Effect of CSC dose.}

The effect of CSC dose for the degradation of Methyl Orange was determined by varying CSC dosage from $0.02 \mathrm{~g}$ to $0.14 \mathrm{~g}$ of CSC at an optimum contact time of 70 minutes. The correlation between CSC dose and the \% of degradation was illustrated in Fig. 3. Methyl Orange degradation increases with an increase in CSC dose up to $0.1 \mathrm{~g}$; this may be attributed to excess availability of active sites, and CSC surface area enhances rapid degradation rate. Further addition of CSC converts the dye solution as turbid and non-transparent due to the CSC agglomeration, which decreases the degradation rate [30]. The maximum degradation $(94.01 \%)$ of Methyl Orange was achieved by using $0.1 \mathrm{~g}$ of CSC was fixed as an optimum dose for photocatalytic degradation studies.

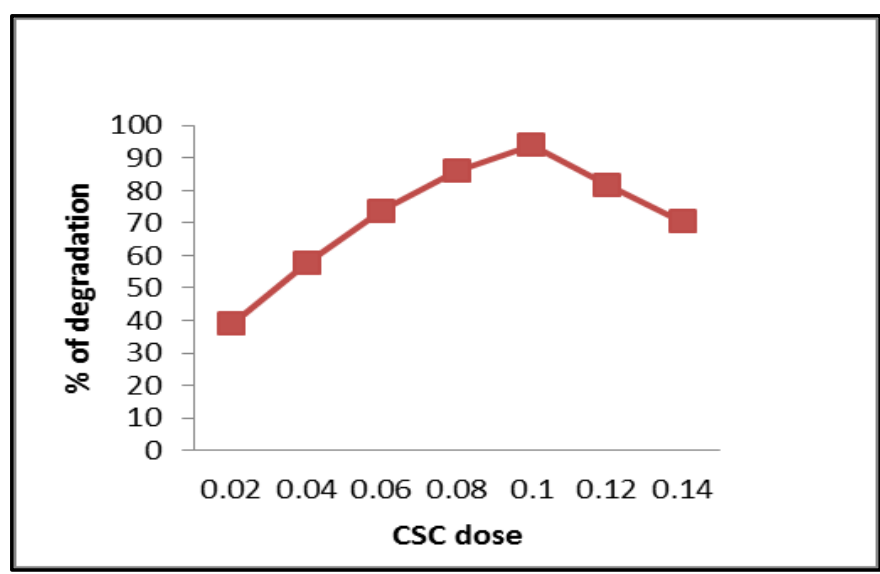

Figure 3. Effect of CSC dose on Methyl Orange degradation. 


\subsubsection{Effect of dye concentration.}

The effect of dye concentration onto CSC was determined by varying Methyl Orange concentration from 10-70 ppm at optimum conditions. A plot of dye concentration and $\%$ degradation was shown in Fig. 4. The $\%$ of degradation decreases by increasing the dye concentration. The $\%$ of degradation decreased from $94.01 \%$ to $35.41 \%$. The results revealed that a fixed amount of CSC uptake only fixed quantity of dye from solution remaining dye will be as such in the solution, which decreases the composite's oxidizing ability was the primary reason for a decrease in dye degradation at higher concentration [31].

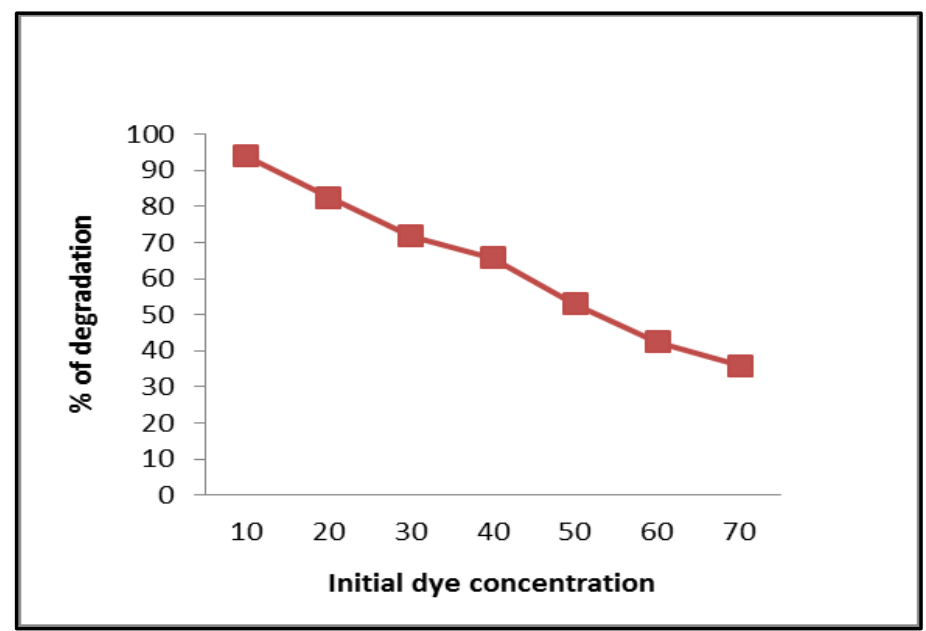

Figure 4. Effect of dye concentration on methyl orange degradation onto CSC.

\subsubsection{Confirmation analysis for Methyl Orange dye degradation onto CSC.}

The degradation of Methyl Orange onto CSC using sunlight irradiation was confirmed by UV-spectral analysis. The absorbance intensity of Methyl Orange has measured at the wavelength of $464 \mathrm{~nm}$. Initially, the peak value was measured for a blank dye solution. After equilibrium time, the Methyl Orange dye solution with CSC was exposed to direct sunlight. The absorbance was measured for the exposed solution at a regular interval of 10 minutes up to 80 minutes. The decrease in absorbance peak revealed that the peak diminishes concerning time was the confirmation analysis for Methyl Orange degradation. It was shown in Fig. 5. The degradation of Methyl Orange onto CSC before and after treatment at optimum conditions was shown in Fig. 6.

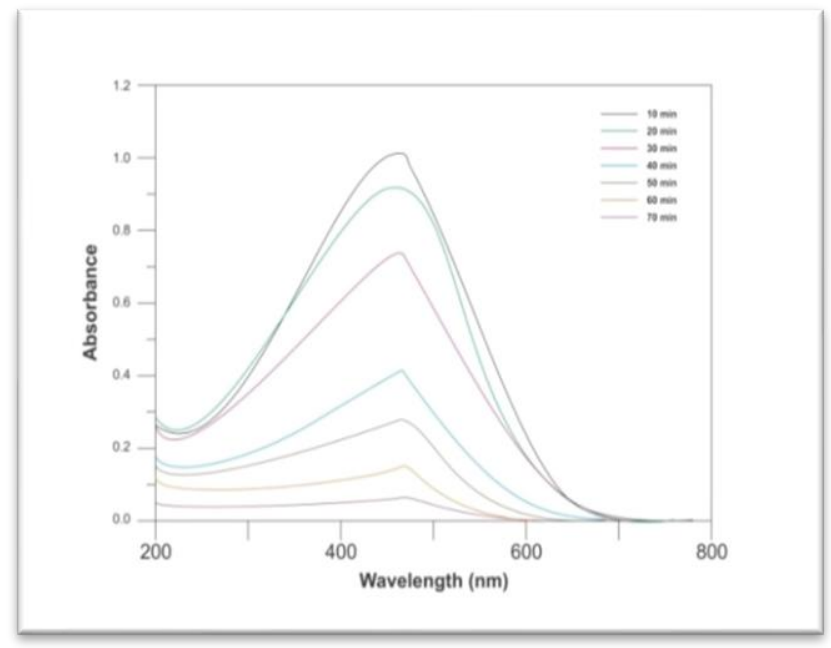

Figure 5. UV absorption spectra for the Degradation of Methyl Orange onto CSC. 
The photocatalytic activity of CSC was assessed by photocatalytic degradation of MO dye under UV irradiation at different time intervals, and the decrease in the absorbance at 464 $\mathrm{nm}$ was monitored at regular time intervals. The disappearance of the $474 \mathrm{~nm}$ absorption peak (Fig. 5) shows that the $-\mathrm{N}=\mathrm{N}$ - bonding is completely decomposed, corresponding to the orange color's disappearance in the solution after the degradation reaction [32]. It is clearly evident that there is a significant decline in the absorbance intensity with irradiation time, making it clear that there is a decrease in the concentration of the MO dye solution suggesting detectable degradation of MO in the presence of the CSC photocatalyst. The CSC's degradation efficiency for MO was observed to be $94 \%$ in $70 \mathrm{~min}$, so MO was completely degraded. Hence it can be used as a beneficial material in the degradation process of dye wastewater. It is clear from Fig. 5 .

\subsubsection{Comparative analysis of various materials for the removal of Methyl Orange dye.}

The degradation efficiency of various materials was compared with the present study material and tabulated in Table 1. The result reveals that the degradation percentage of CSC was high compared to other materials showing the effectiveness of CSC towards Methyl Orange degradation.

Table 1. Comparative analysis of various materials with present study composite.

\begin{tabular}{|l|l|l|}
\hline Photocatalyst & $\begin{array}{l}\text { Time taken for degradation and } \\
\text { method used }\end{array}$ & $\begin{array}{l}\text { Degradation } \\
\text { efficiency }(\%)\end{array}$ \\
\hline Chitosan/kaolin $/ \gamma-\mathrm{Fe}_{2} \mathrm{O}_{3}$ composites & $\begin{array}{l}\text { 3 hours } \\
\text { Solar irradiation }\end{array}$ & 71 \\
\hline Chitosan-g-Poly (acrylamide)/ZnS & $\begin{array}{l}4 \text { hours } \\
\text { Solar irradiation }\end{array}$ & 69 \\
\hline Chitosan/MgO composite & $\begin{array}{l}24 \text { hours } \\
\text { adsorption }\end{array}$ & 93 \\
\hline Core-ShellFe $\mathrm{O}_{4} / \mathrm{SiO}_{2} / \mathrm{TiO}_{2}$ Nanospheres & $\begin{array}{l}\text { 5 hours } \\
\text { UV irradiation }\end{array}$ & 90.20 \\
\hline $\begin{array}{l}\text { Chitosan } \mathrm{Silica} \text { Composite } \\
\text { present study) }\end{array}$ & $\begin{array}{l}\mathbf{7 0} \text { minutes } \\
\text { Solar irradiation }\end{array}$ & $\mathbf{9 4 . 0 1}$ \\
\hline
\end{tabular}

\subsection{Adsorption isotherm studies.}

Generally, adsorption isotherm is used to understand the relationship between adsorbent and adsorbate. The amount of dye adsorbed per unit weight of composite and dye concentration in the aqueous phase at equilibrium condition. The thermodynamics of MO adsorption onto CSC was examined by Langmuir and Freundlich adsorption isotherm.

Langmuir isotherm was used to conclude the monolayer formation of composite over the adsorbate surface. Langmuir model describes the adsorbate's monolayer formation onto the adsorbent's surface. It explores the similar binding energies of the adsorbent's active sites [33]. The Langmuir adsorption isotherm was given in equation 2.

$$
\frac{C_{e}}{q_{e}}=\frac{1}{q_{\max }} b+\frac{C_{e}}{q_{\max }}
$$

Where $\mathrm{C}_{e}$ was the concentration of Methyl Orange dye solution $(\mathrm{mg} / \mathrm{L})$, $\mathrm{q}_{\mathrm{e}}$ was dye concentration onto CSC (mg/g), qmax was the maximum degradation capacity (mg/g) and b was Langmuir equilibrium constant [34]. The result showed that the experimental data were well fitted with the calculated value indicating monolayer formation over the dyed surface. Hence the adsorption of Methyl Orange onto CSC obeys Langmuir adsorption isotherm. The regression correlation coefficient $\left(\mathrm{R}^{2}\right)$ was 0.9967 , and the maximum adsorption capacity ( $\mathrm{q}_{\max }$ )was $12.19 \mathrm{mg} / \mathrm{g}$. The relationship between $\mathrm{C}_{\mathrm{e}}$ and $\mathrm{C}_{\mathrm{e}} / \mathrm{q}_{\mathrm{e}}$ was given in Figure 6. 
Freundlich adsorption isotherm used to study the formation of a heterogeneous layer of composite over the adsorbate surface [35]. It was given by the heterogeneity factor $1 / \mathrm{n}$. The linear form of Freundlich adsorption isotherm was given in equation 3.

$$
\log q_{e}=\frac{1}{n} \log \left(C_{e}\right)+\log K_{f}
$$

hence the Freundlich constant $\mathrm{K}_{\mathrm{f}}(\mathrm{mg} / \mathrm{g})$ and was the Freundlich exponent(n) [36]. The correlation coefficient $\left(\mathrm{R}^{2}\right)$ was 0.9032 , and the heterogeneity factor $1 / \mathrm{n}$ was 4.17 . The results revealed that the experimental value was a poor fit. The calculated value indicates the absence of heterogeneity on the composite surface. Therefore Freundlich adsorption isotherm was unfavorable to the adsorption of Methyl Orange onto CSC. The relationship between $\log \mathrm{C}_{\mathrm{e}} \mathrm{vs}$ $\log \mathrm{q}_{\mathrm{e}}$ was shown in Fig. 7. The isotherm parameters were tabulated in Table 2.

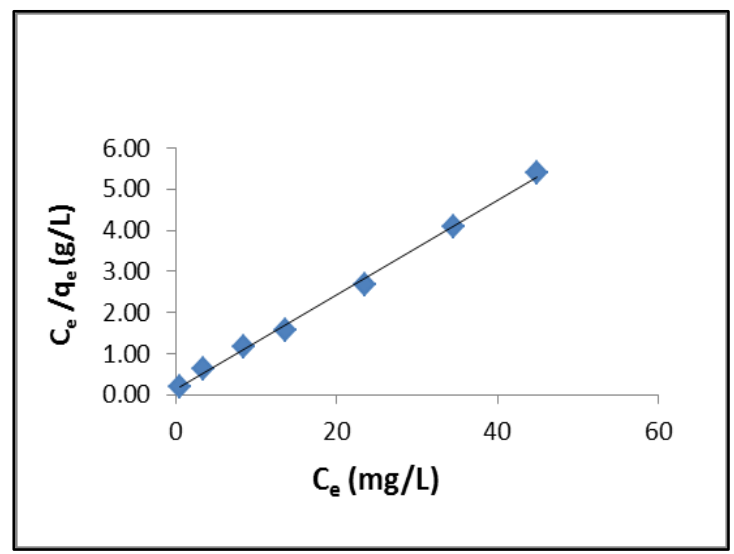

Figure 6. Langmuir isotherm for the adsorption of Methyl Orange onto CSC.

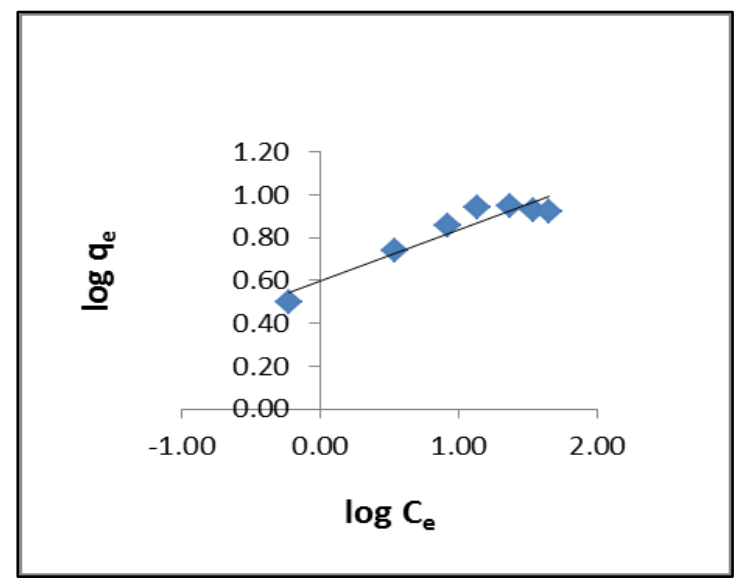

Figure 7. Freundlich isotherm for the adsorption of Methyl Orange onto CSC.

Table 2. Langmuir and Freundlich Isotherm Parameters.

\begin{tabular}{|l|l|l|}
\hline Isotherm Model & Parameters & CSC \\
\hline \multirow{3}{*}{ Langmuir } & $\mathrm{Q}_{\mathrm{m}}(\mathrm{mg} / \mathrm{g})$ & 12.19 \\
\cline { 2 - 3 } & $\mathrm{b}(\mathrm{L} / \mathrm{mg})$ & 3.02 \\
\cline { 2 - 3 } & $\mathrm{R}^{2}$ & 0.9967 \\
\hline \multirow{3}{*}{ Freundlich } & $1 / \mathrm{n}$ & 4.17 \\
\cline { 2 - 3 } & $\mathrm{K}_{\mathrm{F}}(\mathrm{mg} / \mathrm{g})$ & 3.93 \\
\cline { 2 - 3 } & $\mathrm{R}^{2}$ & 0.9032 \\
\hline
\end{tabular}

\subsection{Kinetic studies.}

The kinetics of the adsorption of Methyl Orange onto CSC was determined by pseudofirst and second-order kinetics. pseudo-first-order kinetics was employed to differentiate dye 
solution concentration from the CSC adsorption capacity. The general equation for the pseudofirst-order equation was depicted in equation 4.

$$
\log \left(q_{e}-q_{t}\right)=\log q_{e}-\frac{K_{1} t}{2.303}
$$

$\mathrm{K}_{1}$ was the first-order rate constant for the adsorption of pseudo-first-order kinetics; $\mathrm{q}_{\mathrm{t}}(\mathrm{mg} / \mathrm{g})$ was the uptake of dye at time $\mathrm{t}$, and $\mathrm{q}_{\max }(\mathrm{mg} / \mathrm{g})$ was the dye uptake at equilibrium[37]. The regression correlation coefficient was 0.8304 , and the maximum adsorption capacity $\mathrm{q}_{\max }$ was $23.12 \mathrm{mg} / \mathrm{g}$ at the equilibrium condition. Based on the results, the experimental data was a poor fit with the calculated value. The pseudo-first-order equation was less favorable for the adsorption of Methyl Orange onto CSC. The relationship was correlated by a graph plotted between time ( $\mathrm{t}$ in minutes) and $\log \mathrm{q}_{\mathrm{e}}-\mathrm{q}_{\mathrm{e}}$ was shown in Fig. 8.

Ho and Mckay developed the pseudo-second-order kinetic equation, and the general equation of second-order kinetics was given in equation 5. A plot of time ( $\mathrm{t}$ in minutes) and $\mathrm{t} / \mathrm{q}$ gives a straight line, which was shown in Fig. 9.

$$
\frac{\mathrm{t}}{q_{t}}=\frac{1}{K_{2}}-\frac{t}{q_{e}}
$$

where $\mathrm{K}_{2}$ was the equilibrium rate constant $(\mathrm{g} / \mathrm{mg} \min )$, $\mathrm{q}_{\mathrm{t}}$ was the uptake of dye at moment $\mathrm{t}$, and $\mathrm{q}_{\mathrm{e}}$ was the amount of dye adsorbed at equilibrium time [38]. The regression correlation coefficient $\left(\mathrm{R}^{2}\right)$ was 0.9924 , and the maximum adsorption capacity $\mathrm{q}_{\max }$ was $72.46 \mathrm{mg} / \mathrm{g}$. The experimental values were very close to the calculated values indicate that the adsorption was well fitted for the pseudo-second-order kinetics equation. It gives the ion exchange interaction between CSC and Methyl Orange may also affect the adsorption [39]. The kinetic parameters were summarized in Table 3.

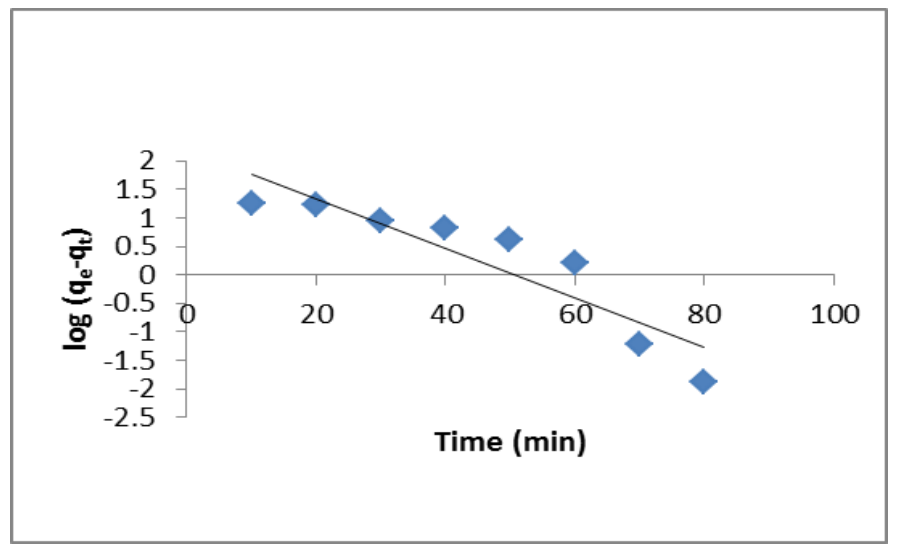

Figure 8. Pseudo-first-order kinetics for the adsorption of Methyl Orange onto CSC.

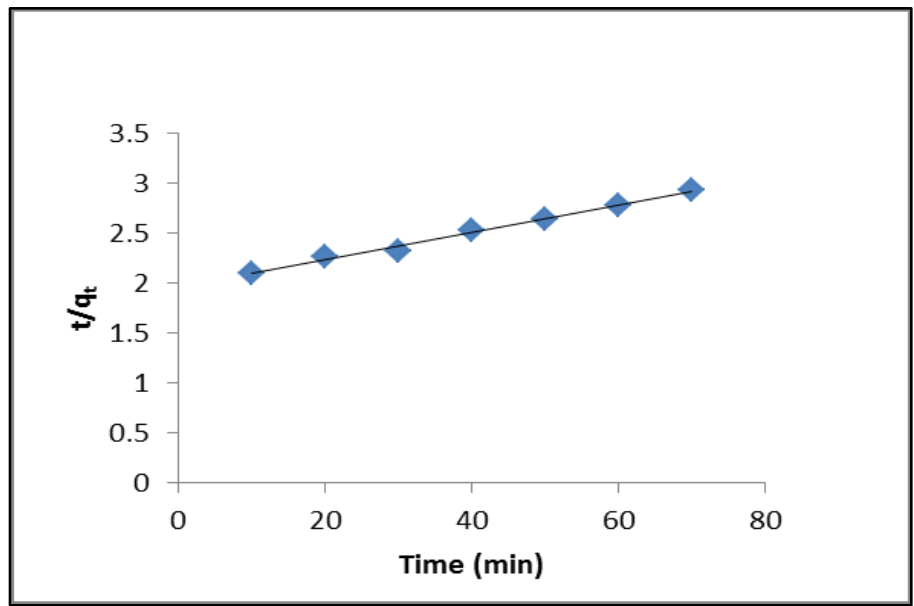

Figure 9. Pseudo-second-order kinetics for the adsorption of Methyl Orange onto CSC. 
Table 3. Kinetic parameters for the adsorption of Methyl Orange onto CSC.

\begin{tabular}{l|l|l} 
Kinetic model & Parameter & CSC \\
\hline \multirow{3}{*}{ Pseudo first order } & $\mathrm{k}_{1}\left(\mathrm{~min}^{-1}\right)$ & 0.1004 \\
\cline { 2 - 3 } & $\mathrm{q}_{\mathrm{e}}(\mathrm{mg} / \mathrm{g})$ & 23.12 \\
\cline { 2 - 3 } & $\mathrm{R}^{2}$ & 0.8304 \\
\hline \multirow{4}{*}{ Pseudo second order } & $\mathrm{k}_{2}(\mathrm{~g} / \mathrm{mg} \min )$ & 0.00009 \\
\cline { 2 - 3 } & $\mathrm{q}_{\mathrm{e}}(\mathrm{mg} / \mathrm{g})$ & 72.46 \\
\cline { 2 - 3 } & $\mathrm{h}$ & 0.47 \\
\cline { 2 - 3 } & $\mathrm{R}^{2}$ & 0.9924
\end{tabular}

\section{Conclusions}

Based on the results of photocatalytic degradation of Methyl Orange onto CSC, the modified Chitosan Silica Composite was prepared successfully and utilized for the degradation of Methyl Orange using sunlight as the irradiating source. Photocatalytic degradation studies were carried out to determine the optimum conditions by varying contact time, $\mathrm{pH}, \mathrm{CSC}$ dose, and dye concentration. The maximum degradation of Methyl Orange (94.01\%), was achieved at the contact time of 70 minutes at $\mathrm{pH} 4$. According to the previous literature, the percentage of degradation was high for anionic dyes than cationic dyes. The optimum initial dye concentration of MO dye was fixed as $10 \mathrm{ppm}$, and the optimum dose of CSC was $0.1 \mathrm{~g}$. UVVisible spectroscopic studies confirmed the degradation. The equilibrium data obtained from the result was very close to the calculated value proves that the adsorption of Methyl Orange onto CSC obeys Langmuir adsorption isotherm; hence the formation of strong monolayer occurs over the homogeneous surface. The adsorption depends upon the initial dye concentration and composite dose, so it follows pseudo-second-order kinetics. Based on the above conclusions, CSC could be effectively used as a photocatalyst for Methyl Orange degradation using sunlight irradiation.

\section{Funding}

This research received no external funding.

\section{Acknowledgments}

This research has no acknowledgment.

\section{Conflicts of Interest}

The authors declare no conflict of interest.

\section{References}

1. Abram, F.S.H.; Sims, I.R. The Toxicity of Aniline to Rainbow Trout. Water Research 1982, 16, 1309-1312, https://doi.org/10.1016/0043-1354(82)90208-1.

2. Bahrudin, N.N.; Nawi, M.A. Mechanistic of photocatalytic decolorization and mineralization of methyl orange dye by immobilized TiO2/chitosan-montmorillonite. Journal of Water Process Engineering 2019, 31, https://doi.org/10.1016/j.jwpe.2019.100843.

3. Niu, P. Photocatalytic Degradation of Methyl Orange in Aqueous $\mathrm{TiO}_{2}$ Suspensions. Asian Journal of Chemistry 2013, 25, 1103-1106, https://doi.org/10.1016/j.chemosphere.2007.05.021.

4. Nair, P.; Vijayakumar, S.; Lisluke, T.; Mathew, M.; Aravindakumar, C. Degradation of Dyestuff Pollutant Sudan I Using Advanced Oxidation Process. Journal of Water Resource and Protection 2014, 6, 1276-1283, https://doi.org/10.4236/jwarp.2014.614117.

5. Ghorbani, M.; Seyedin, O.; Aghamohammadhassan, M.; Adsorptive removal of lead (II) ion from water and wastewater media using carbon-based nanomaterials as unique sorbents: A review. J Environ Manage, 2020, 254, https://doi.org/10.1016/j.jenvman.2019.109814. 
6. Demissie, H.; An, G.; Jiao, R.; Ritigala, T.; Lu, S.; Wang, D.; Modification of high content nanocluster-based coagulation for rapid removal of dye from water and the mechanism, Separation and Purification Technology, 2020, doi: https://doi.org/10.1016/j.seppur.2020.117845.

7. Wang, W.-L.; Hu, H.-Y.; Liu, X.; Shi, H.-X.; Zhou, T.-H.; Wang, C.; Huo, Z.-Y.; Wu, Q.-Y. Combination of catalytic ozonation by regenerated granular activated carbon (rGAC) and biological activated carbon in the advanced treatment of textile wastewater for reclamation. Chemosphere, 2019, 231, 369-377. https://doi.org/10.1016/j.chemosphere.2019.05.175.

8. Sajjad, A.-A.; Yunus, M. Y. B. M.; Azoddein, A. A. M.; Hassell, D. G.; Dakhil, I. H.; \& Hasan, H. A. Electrodialysis Desalination for Water and Wastewater: A Review. Chemical Engineering Journal, 2019, 122231, https://doi.org/10.1016/j.cej.2019.122231.

9. Liu, G.; Abukhadra, M.R.; El-Sherbeeny, A.M.; Mostafa, A.M.; Elmeligy, M.A. Insight into the photocatalytic properties of diatomite@ $\mathrm{Ni} / \mathrm{NiO}$ composite for effective photo-degradation of malachite green dye and photoreduction of $\mathrm{Cr}$ (VI) under visible light. J Environ Manage, 2020, 254, 109799. https://doi.org/10.1016/j.jenvman.2019.109799.

10. Sakthivel, S.; Neppolian, B.; Shankar, M.V.; Arabindoo, B.; Palanichamy, M.; Murugesan, V. Solar photocatalytic degradation of azo dye: Comparison of photo catalytic efficiency of $\mathrm{ZnO}$ and $\mathrm{TiO}_{2}$ Solar Energy Material Cells, 2003, 77, 65-82, https://doi.org/10.1016/S0927-0248(02)00255-6.

11. Momeni, M.; Ghayeb, Y.; Gheibee, S. Silver nanoparticles decorated titanium dioxide tungsten trioxide nanotube films with enhanced visible light photo catalytic activity. Ceramic International, 2017, 43, 564-570, https://doi.org/10.1016/j.ceramint.2016.09.195.

12. Zhu, H.-Y.; Jiang, R.; Xiao, L. Adsorption of an anionic azo dye by chitosan/kaolin/ $\gamma$-Fe2O3 composites. Applied Clay Science, 2010, 48, 522-526, https://doi.org/10.1016/j.clay.2010.02.003.

13. Pathania, D.; Gupta, D.; Al-Muhtaseb, A.a.H.; Sharma, G.; Kumar, A.; Naushad, M.; Ahamad, T.; Alshehri, S.M. Photocatalytic degradation of highly toxic dyes using chitosan-g-poly(acrylamide)/ZnS in presence of solar irradiation. Journal of Photochemistry and Photobiology A: Chemistry, 2016, 329, 61-68, https://doi.org/10.1016/j.jphotochem.2016.06.019.

14. Haldorai, Y.; Shim, J.J. An efficient removal of methyl orange dye from aqueous solution by adsorption onto chitosan/MgO composite: A novel reusable adsorbent. Applied Surface Science 2014, 292, 447-453, https://doi.org/10.1016/j.apsusc.2013.11.158.

15. Alzahrani, E. Photodegradation of Binary Azo Dyes using Core-shell $\mathrm{Fe}_{3} \mathrm{O}_{4} / \mathrm{SiO}_{2} / \mathrm{TiO}_{2}$ Nanospheres. American Journal of Analytical Chemistry 2017, 8, 95-115, https://doi.org/10.4236/ajac.2017.81008.

16. Mazumder, N.A.; Rano, R. Synthesis and Characterization of Fly Ash Modified Copper Oxide (FA/CuO) for Photocatalytic Degradation of Methyl Orange Dye. Materials Today: Proceedings 2018, 5, 2281-2286, https://doi.org/10.1016/j.matpr.2017.09.230.

17. Habiba, U.; Siddique, T.A.; Li Lee, J.J.; Joo, T.C.; Ang, B.C.; Afifi, A.M. Adsorption study of methyl orange by chitosan/polyvinyl alcohol/zeolite electrospun composite nanofibrous membrane. Carbohydrate Polymers, 2018, 191, 79-85, https://doi.org/10.1016/j.carbpol.2018.02.081.

18. Kyzas, G.Z.; Bikiaris, D.N. Recent Modifications of Chitosan for Adsorption Applications, A Critical and Systematic Review. Marine Drugs 2015, 13, 312-337, https://doi.org/10.3390/md13010312.

19. Budnyak, T.M.; Pylypchuk, I.V.; Tertykh, V.A.; Yanovska, E.S.; Kolodynska, D. Synthesis and adsorption properties of chitosan-silica nanocomposite prepared by sol-gel method. Nanoscale Research Letters, 2015, 10, https://doi.org/10.1186/s11671-014-0722-1.

20. He, H.; Meng, X.; Yue, Q.; Yin, W.; Gao, Y.; Fang, P.; Shen, L. Thiol-ene click chemistry synthesis of a novel magnetic mesoporous silica/chitosan composite for selective $\mathrm{Hg}$ (II) capture and high catalytic activity of spent Hg(II) adsorbent. Chemical Engineering Journal, 2021, 405, https://doi.org/10.1016/j.cej.2020.126743.

21. Shan, W.; Zhang, D.; Wang, X.; Wang, D.; Xing, Z.; Xiong, Y.; Fan, Y.; Yang, Y. One-pot synthesis of mesoporous chitosan-silica composite from sodium silicate for application in Rhenium(VII) adsorption. Microporous and Mesoporous Materials, 2019, 278, 44-53, https://doi.org/10.1016/j.micromeso.2018.10.030.

22. Blachnio, M.; Budnyak, T.M.; Derylo-Marczewska, A.; Marczewski, A.W.; Tertykh, V.A. Chitosan-Silica Hybrid Composites for Removal of Sulfonated Azo Dyes from Aqueous Solutions. Langmuir, 2018, 34, 2258- 2273, https://doi.org/10.1021/acs.langmuir.7b04076.

23. Joshi, S.; Srivastava, R.K. Adsorptive removal of lead $(\mathrm{Pb})$, copper $(\mathrm{Cu})$, nickel $(\mathrm{Ni})$ and mercury $(\mathrm{Hg})$ ions from water using chitosan silica gel composite. Environmental Monitoring and Assessment, 2019, 191, https://doi.org/10.1007/s10661-019-7777-5.

24. Saraswathi, P.; Makeswari, M. Preparation and characterization of Alumina and Silica modified Chitosan. Rasayan Journal of Chemistry, 2017, 10, 759-765, http://dx.doi.org/10.7324/RJC.2017.1031752.

25. Liu, Y.; Cai, Z.; Sheng, L.; Ma, M.; \& Xu, Q. Influence of nanosilica on inner structure and performance of chitosan based films. Carbohydrate Polymers, 2019, 212, 421-429. https://doi.org/10.1016/j.carbpol.2019.04.001

26. Dhir, R. Photocatalytic degradation of methyl orange dye under UV irradiation in the presence of Synthesized PVP capped pure and gadolinium doped $\mathrm{ZnO}$ nanoparticles. Chemical Physics Letters, 2020, 746, https://doi.org/10.1016/j.cplett.2020.137302. 
27. Madhusudhana, N.; Yogendra, K.; Mahadevan. K.M. Photo catalytic Degradation of Violet GL2B Azo dye By using Calcium Aluminate Nanoparticle in presence of Solar light. Research Journal of Chemical Sciences, 2012, 2, 72-77.

28. Khorramfar, S.; Mahmoodi, N.M.; Arami, M.; Gharanjig, K. Equilibrium and Kinetic Studies of the Cationic Dye Removal Capability of a Novel Biosorbent Tamarindus Indica from Textile Wastewater. Coloration Technology 2010, 126, 261- 268, https://doi.org/10.1111/j.1478-4408.2010.00256.x.

29. Sharma, N.; Tiwari, D.P.; Singh, S.K. Decolourisation of Synthetic Dye by Agricultural Waste- A Review. International Journal of Scientific \& Engineering Research, 2012, 3, 385- 394.

30. Garg, V.K.; Kumar, R.; Gupta, R. Removal of malachite green dye from aqueous solution by adsorption Using agro industry waste: a case study of Prosopis cineraria. Dyes and Pigments, 2004, 62, 1-10, https://doi.org/10.1016/j.dyepig.2003.10.016.

31. Rathore, R.; Ameta, R.; Suresh, C.A. Photo catalytic degradation of malachite green over nickel vanadate powder. Acta Chimica pharmaceutica Indica, 2014, 4, 213-220.

32. Radini, I.A.; Hasan, N.; Malik, M.A.; Khan, Z. Biosynthesis of iron nanoparticles using Trigonella foenumgraecum seed extract for photocatalytic methyl orange dye degradation and antibacterial applications. Journal of Photochemistry and Photobiology B: Biology, 2018, 183, 154-163, https://doi.org/10.1016/j.jphotobiol.2018.04.014.

33. Liu, S.; Chen, M., Cao, X.; Li, G.; Zhang, D.; Li, M.; Meng, N.; Yin, J., Yan, B.; Chromium (VI) removal from water using cetylpyridinium chloride (CPC)- modified montmorillonite. Separation and Purification Technology, 2020. 241, 116732, https://doi.org/10.1016/j.seppur.2020.116732.

34. Langmuir, I. The Adsorption Of Gases On Plane Surfaces Of Glass, Mica And Platinum. Journal of the American Chemical Society 1918, 40, 1361-1403, https://doi.org/10.1021/ja02242a004.

35. Boulaiche, W.; Hamdi, B.; Trari, M.; Removal of heavy metals by chitin: Equilibrium, kinetic and thermodynamic studies. Applied Water Science, 2019, 9, 39.

36. Freundlich, H. Uber die adsorption in losungen (Adsorption in solution). Journal of Physical Chemistry 1906, 57, 384-470.

37. Ho, Y.S.; Mckay, G. Sorption of dye from aqueous solution by peat. Chemical Engineering Journal, 1998a, 70, 115-124, https://doi.org/10.1016/S0923-0467(98)00076-1.

38. Ho, Y.S.; Mckay, G. Kinetic models for the sorption of dye from aqueous solution by wood. Journal of Environ Science Health Part B: Process Safe Environment Protection 1998, 76, 183-191, https://doi.org/10.1205/095758298529326.

39. Mahmoud, M.E., El-Said, G.F., Rashedy, I.R.K., Abdelfattah, A.M., Assembly and implementation of an ecofriendly marine nanosediment for adsorptive removal of heptavalent manganese: Adsorption isotherm, thermodynamic and kinetics studies. Powder Technology 2020, 359, 247-260, https://doi.org/10.1016/j.powtec.2019.09.063. 